\title{
Um Banco de Dados de Entalpias de Vaporização e de Sublimação
}

\author{
Hermínio P. Diogo, Madalena Dionísio, \\ Adelino M. Galvão e \\ José A. Martinho Simððes a
}

\section{Introdução}

O grande volume de resultados experimentais em muitas áreas da Química tem catalisado a criação de bancos de dados. O "Cambridge Data File», dedicado à compilação de dados estruturais de moléculas, é talvez o exemplo mais conhecido, mas existem muitos outros conjuntos de valores experimentais arquivados em memoria de computadores. Os benefícios de tais bancos de dados não se limitam ao acesso simples e rápido de toda a informação disponível. Talvez mais importante que isso, permitem realizar as chamadas buscas selectivas.

Para citar um caso de uma busca selectiva pode recorrer-se ao banco de dados descrito nesta nota, o qual consiste numa compilação de valores experimentais de entalpias de vaporização e de sublimação padrão de substâncias orgânicas. Por exemplo, é fácil agrupar numa folha de papel os valores referentes aos tiois lineares (Fig. 1) e estudar a variação da entalpia de vaporização padrão com o tamanho da cadeia (Fig. 2). As inúmeras possibilidades de correlaçס̄es deste tipo que se podem obter sem gastos de tempo e esforço, proporcionam uma melhor compreensão da natureza da propriedade em estudo, em particular a sua relação com a estrutura molecular. Como resultado, podem aperfeiçoar-se métodos de estimativa.

Uma base de dados como a que se apresenta deve obedecer a alguns requisitos. Primeiro, deve ser crítica e exaustiva, isto é, deve conter todos os valores disponiveis que mereçam confiança; segundo, deve poder ser actualizada; terceiro, deve ser versátil, proporcionando vários tipos de buscas selectivas; quarto, não deve depender dos conhecimentos informáticos do utilizador, a nível de programação.

\section{Base de Dados}

O programa que gere a base de dados de entalpias de vaporização está preparado para funcionar num micro-computador DIGITAL (Rainbow), apenas equipado com disquetes de $400 \mathrm{~K}$. Os ficheiros de dados anexos ao programa incluem cerca de 1300 compostos e 41 "termos» (símbolos que englobam as funçðes químicas e características estruturais), podendo ambos ser actualizados tanto no que diz respeito a novos compostos como a novos termos. A listagem da Fig. 1 foi obtida recorrendo a três termos: «n-» (indicando cadeia linear), "Vap» (pretendia-se excluir sólidos) e «SH» (função tiol).

Como se ilustra no exemplo, o programa encontra-se estruturado de forma a que o utilizador possa pesquisar um determinado composto (ou classe de compostos), através das funçб̃es químicas e/ou das características estruturais nele presentes. Nos ficheiros cada molécula foi classificada tendo em conta os seus grupos funcionais e as suas características estruturais (e.g., número de átomos de carbono, estrutura da cadeia - linear, ramificada ou cíclica - e função química - ácido, tiol, etc.). A actualização do banco de dados, pode ser conseguida directamente através do programa e, se necessário, pela definição de funçð̃es químicas ou outras características estruturais inexistentes no ficheiro.

A visualização da informação armazenada, tanto de compostos como de termos, pode ser obtida directamente no ecran ou por listagem em impressora.

O programa efectua uma série de testes aos valores introduzidos, por forma a evitar a armazenagem de dados incorrectos, permitindo a alteração destes em caso de erro. Contudo, a correcção do ficheiro, após introdução, só pode ser efectuada através do sistema operativo ou "software» equivalente.

Os sócios da S.P.Q. que desejarem possuir o banco de dados em causa, incluindo um pequeno manual de utilização, devem enviar uma disquete de 5" 1/4 para um dos autores.

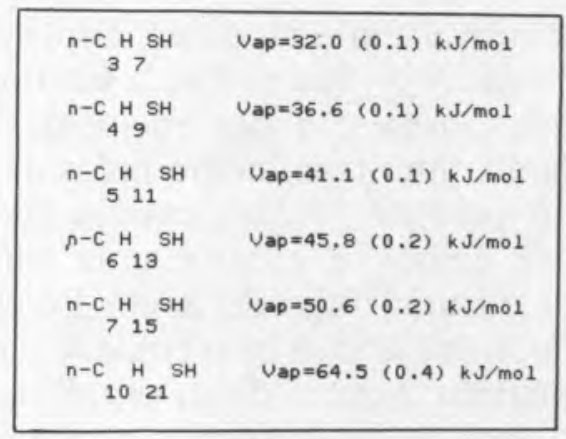

Fig. 1

"Output" de uma busca selectiva da entalpia de vaporização dos tióis de cadeia linear

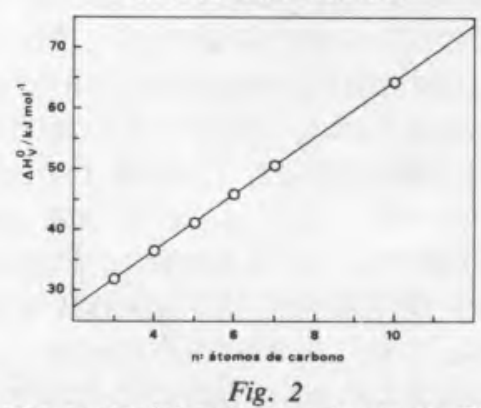

Correlaçâo entre as entalpias de vaporização da Fig. 1 e o número de átomos de carbono $(N)$. Os valores experimentais para $N=8 \mathrm{e} 9$ não constam no banco de dados, mas, como se vê, a sua estimativa pode ser feita com rigor

a Centro de Química Estrutural, Complexo I, Instituto Superior Técnico, 1096 Lisboa Codex, Portugal. 